\title{
MÉTODOS DE ENSINO DE EMPREENDEDORISMO EM INSTITUIÇÕES DE ENSINO SUPERIOR
}

Elisângela Modesto Silva ${ }^{1}$

Sandra Regina Holanda Mariano ${ }^{2}$

\footnotetext{
${ }^{1}$ Programa de Pós-Graduação Mestrado e Doutorado / Universidade Federal Fluminense

${ }^{2}$ Universidade Federal Fluminense
} 


\section{MÉTODOS DE ENSINO DE EMPREENDEDORISMO EM INSTITUIÇÕES DE ENSINO SUPERIOR}

\section{Resumo}

Este estudo tem como objetivo apresentar e discutir as metodologias de ensino de empreendedorismo adotadas nas instituições de ensino superior (IES) em suas ações de educação empreendedora. O levantamento considerou artigos científicos publicados entre os anos 2000 e 2017. Foram identificados 83 artigos que abordaram o tema de interesse, dos quais 18 tratavam especificamente de métodos de ensino de empreendedorismo. Os achados indicaram que as abordagens que utilizam métodos experienciais de ensino ficaram em maior evidência nos artigos publicados a partir do ano de 2010. Entretanto, os métodos tradicionais de ensino de empreendedorismo, como elaboração de planos de negócios, palestras sobre o tema, debates em sala de aula se mantém como abordagens utilizadas para despertar a consciência empreendedora nos alunos. O prestígio conquistados por métodos experienciais entre os pesquisadores da área, a sua implementação nas IES parece ser marginal.

Palavras-chave: Ensino de Empreendedorismo. Educação Empreendedora.

Empreendedorismo. Universidade. 


\section{Introdução}

A primeira iniciativa de ensino formal de empreendedorismo parece ter ocorrido nos Estados Unidos, em 1947, na Escola de Administração de Harvard. O programa teve o intuito de qualificar ex-combatentes da Segunda Guerra Mundial, de modo a facilitar a sua reinserção no mercado de trabalho. A partir da década de 1970, o ensino de empreendedorismo se estabeleceu nas escolas de negócios dos Estados Unidos, pela oferta de disciplina com créditos acadêmicos reconhecidos (Kuratko, 2005).

Desde então, programas de educação empreendedora vêm sendo implementados em todo mundo nas últimas décadas (Kuratko, 2005; Béchard e Grégoire, 2005; Fayolle, 2013). Enquanto esses programas são frequentemente oferecidos em universidades, há também o surgimento de inciativas em escolas de ensino fundamental e médio, além da realização de pesquisas e eventos com foco em educação empreendedora. Ainda que haja um crescente interesse em educação empreendedora, não há consenso sobre quais são exatamente os componentes de um modelo prático de qualidade de educação superior empreendedora (Vanevenhoven e Liguori, 2013).

Historicamente, uma variedade de curriculuns e métodos de ensino tem sido usados em todos os tipos de cursos de empreendedorismo em nível superior (Rideout e Gray, 2013). Atualmente, as práticas pedagógicas em educação empreendedora parecem ser um pouco ecléticas e diversificadas, embora as abordagens como, gerenciamento de pequenos negócios, as tradicionais palestras e estudo de casos, continuem sendo bastante aplicadas, observa-se uma tendência ao crescimento das práticas de tecnoempreendedorismo, ensino andragógico e experiencial por meio de jogos, simulações e até mesmo criações de risco real.

Estas abordagens se originam, em grande medida, do campo da pesquisa em empreendedorismo e seus métodos de ensino são inspirados pelas habilidades as quais empreendedores usam e as maneiras pelas quais empreendedores aprendem (Moberg, 2014).

Em Fayolle (2013) questões didáticas e educacionais importantes são levantadas: (i) O que estamos dizendo quando falamos sobre Educação Empreendedora? (ii) O que estamos realmente fazendo quando ensinamos ou educamos pessoas para o empreendedorismo, em termos de natureza e do impacto de nossas intervenções? (iii) o que sabemos sobre a apropriação, a relevância, a coerência, a utilidade social e a eficiência de nossas iniciativas e práticas em educação empreendedora? As respostas para tais questionamentos não são triviais, conforme assevera Moberg (2014, p.7) "pesquisa em empreendedorismo é um campo heterogêneo, e, consequentemente, há numerosas abordagens para educação empreendedora. Pouco é sabido sobre a eficácia dessas abordagens, e muita confusão conceitual e de definição torna complicado comparar as diferentes inciativas no campo".

Fayolle também pontua que precisamos de sólidos fundamentos teóricos e conceituais, baseados nos campos de empreendedorismo e educação, para apoiar programas e cursos de empreendedorismo. Entretanto, precisamos refletir sobre nossas práticas e assumir uma posição mais crítica, no que diz respeito a perfil de participantes e conhecimentos de educadores em termos de objetivos, conteúdos, métodos e resultados esperados. Essas escolhas também dependem das condições institucionais (oportunidades e restrições em termos de cultura, espaço alocado, tempo, apoio, recursos, etc.).

Em sua revisão bibliográfica, Fayolle, 2013, aponta que os conteúdos são frequentemente baseados nos livros de texto mais populares sobre empreendedorismo e tendem a refletir a natureza (centrada na oportunidade) e a dinâmica do processo empresarial, entretanto, há uma lacuna entre o que se ensina e o que os empresários fazem. E no que se 
refere a metodologias, a literatura destaca o que se chama de ensino empreendedor, baseado nas pedagogias "ativas", "experienciais", "aprender fazendo" e "mundo real".

Baseado nisso, este estudo objetiva identificar e analisar, por meio de um estudo bibliométrico nas bases de dados WoS (Web of Science) e Scopus, as metodologias de ensino adotadas pelas instituições de ensino superior para o desenvolvimento da educação empreendedora. O levantamento compreende os anos 2000 e 2017. A análise envolverá a compreensão das abordagens utilizadas para o desenvolvimento das competências empreendedoras do estudante e as principais tendências neste campo.

Além desta introdução, o trabalho foi organizado nas seguintes sessões: educação empreendedora, que traz uma breve revisão da literatura acerca do tema, método de pesquisa, onde é explicado como o estudo foi realizado, análise dos resultados, onde são apresentados os principais achados da pesquisa, na sequencia são apresentadas as conclusão e limitações, e por fim, as referências bibliográficas utilizadas.

\section{Educação empreendedora}

Está ficando claro que o empreendedorismo, ou certas facetas dele, podem ser ensinados. Educadores de negócios e profissionais evoluíram para além do mito que os empresários nascem, e não são "feitos" (Kuratko, 2005). Peter Drucker, reconhecido como um dos principais pensadores gerenciais do nosso tempo, disse: "A mística empresarial? Não é mágico, não é misterioso, e não tem nada a ver com os genes. É uma disciplina. E, como qualquer disciplina, pode ser aprendida "(Drucker, 1985, citado em Kuratko, 2005).

A demanda para o desenvolvimento e oferta de educação empreendedora de alta qualidade tem crescido, na medida em que o empreendedorismo e a inovação foram reconhecidos como fatores críticos para o desenvolvimento sustentável da economia e geração de vantagem competitiva (Winkel, Vanevenhoven, Drago, Clements, 2013). A importância crescente da educação empreendedora tem levado os pesquisadores a buscar maior rigor nas pesquisas para apoiar o desenvolvimento de uma teoria de educação empreendedora. Ainda que haja um crescente interesse em educação empreendedora, não há consenso sobre quais são exatamente os componentes de um modelo prático de qualidade de educação superior empreendedora (Vanevenhoven e Liguori, 2013). Pois, até o momento são poucas as evidências de uma teoria bem articulada neste campo (Rideout e Gray, 2013).

Especialistas em educação empreendedora na União Europeia e nos Estados Unidos pontuam que a atuação empreendedora demanda atitudes e habilidades que são aprendidas de forma sistemática (Lopes, 2010), já para os especialistas do Consórcio para Educação Empreendedora, a educação empreendedora pode ter vários significados de acordo com os níveis educacionais ou escolas vocacionais, em cada nível esperam-se resultados diferentes, conforme os alunos ampliam seu repertório de conhecimento, comportamento e habilidades.

Lopes (2010) recomenda para as IES que desenvolvam as habilidades e técnicas para a identificação e avaliação de oportunidades de negócios, focalizando o desenvolvimento de um plano de negócios real, a criação e o gerenciamento de um negócio. Também é função das IES a implantação de um projeto bem analisado e fundamentado por meio de orientação, consultoria, empréstimos e facilidades para o negócio, fornecendo suporte para ideias desde sua criação até, pelo menos, até seu nascimento e colocação no mercado.

Béchard e Grégoire (2005), apontam 3 modelos de ensino de empreendedorismo para o ensino superior: (i) modelo de oferta - destacam um paradigma comportamental, em termos de "transmissão e reprodução de conhecimento e aplicação de procedimentos" (palestras, 
leitura, observação / escuta), (ii) modelo de demanda - centra-se em métodos pedagógicos que destacam o paradigma subjetivista, envolvendo significado personalizado através da participação em termos de "exploração, discussão e experimentação" e (iii) modelo de competência - que destacam um paradigma teórico interacionista, em termos de resolução ativa de problemas em situações da vida real, onde "o ensino é concebido como uma intervenção estratégica para permitir e influenciar a forma como os alunos organizam os recursos à sua disposição em competências que podem ser mobilizadas para ação. Este modelo enfatiza a "comunicação e discussão" (seminário, apresentações, debates) e a "produção" de conhecimento (ensaios, modelagem, carteiras).

\section{Procedimentos Metodológicos}

Este estudo foi realizado por meio de uma pesquisa bibliométrica, buscando analisar as metodologias de ensino adotadas pelas instituições de ensino superior no desenvolvimento de programas de educação empreendedora.

A bibliometria possui como principal característica permitir a elaboração de índices de produção do conhecimento científico. Sua utilização em pesquisas científicas é pautada na investigação da dinâmica do conhecimento e da literatura como parte dos processos de comunicação acadêmica (Marcelo e Hayashi, 2013).

O presente estudo se caracteriza por ser exploratório e descritivo. Segundo Gil (2002), pesquisas exploratórias proporcionam maior familiaridade com o problema, com vistas a torná-lo mais explícito ou a constituir hipóteses. Também têm como objetivo principal o aprimoramento de ideias ou a descoberta de intuições. Pesquisas descritivas são, juntamente com as exploratórias, as que habitualmente realizam os pesquisadores sociais preocupados com a atuação prática (Gil, 2002), além disso, pesquisas descritivas identificam os fatores que contribuem ou determinam a ocorrência dos fenômenos (Gerhardt e Silveira, 2009).

Para explorar as metodologias de ensino de empreeendeorismo, foram escolhidos termos para a realização da pesquisa, a saber: Entrepren* Education, Entrepren* Education AND Higher Education, Entrepren* Education AND Teaching. $\mathrm{O}$ recorte temporal compreendeu os anos de 2000 a 2017. Foram analisados apenas artigos científicos publicados em revistas acadêmicas.

Após a definição dos termos de busca, elegeu-se as bases de dados WoS (Web of Science) e Scopus para a realização da bibliometria. Estas são as maiores bases de dados multidisciplinares disponíveis, além de possuírem ampla cobertura de revistas de alto impacto. A base de dados WoS (Web of Science) retornou um resultado de busca com 135 artigos e a base de dados Scopus retornou um resultado de busca com 246 artigos.

A análise bibliométrica das duas bases foi realizada utilizando o total de artigos encontrados na pesquisa e os artigos foram classificados por quantidade de citações, anos de publicação e quantidade e países. O passo seguinte foi realizar a leitura de todos os resumos dos artigos identificados nas duas bases. Na sequência, foi realizado download de todos os artigos disponíveis que tratavam sobre educação empreendedora e métodos e abordagens de ensino em Instituições de Ensino Superior. Foram selecionados 35 artigos na base de dados WoS (Web of Science) e 62 artigos na base de Scopus para serem lidos e analisados em profundidade. 


\section{Apresentação e Análise dos Resultados}

Identificou-se 135 artigos na base de dados WoS (Web of Science). A tabela 1 mostra a quantidade de publicações por País e o percentual em relação ao total.

Tabela 1 - Quantidade de Publicações por País e percentual correspondente da base WoS

\begin{tabular}{c|c|c}
\hline País & Artigos & \% de 135 \\
\hline Inglaterra & 23 & 17,03 \\
\hline Estados Unidos & 17 & 12,59 \\
\hline Espanha & 13 & 5,63 \\
\hline Austrália & 8 & 5,92 \\
\hline Brasil & 7 & 5,18 \\
\hline África do Sul & 7 & 4,44 \\
\hline Itália & 6 & 4,44 \\
\hline China & 6 & 3,7 \\
\hline França & 5 & 3,7 \\
\hline Alemanha & 5 & 28,1 \\
\hline Outros & 38 & $\mathbf{1 0 0 \%}$ \\
\hline TOTAL & $\mathbf{1 3 5}$ & \\
\hline
\end{tabular}

Fonte: Dados da Pesquisa (2017)

Identificou-se 246 artigos na base de dados Scopus. A tabela 2 mostra a quantidade de publicações por País e o percentual em relação ao total.

Tabela 2 - Quantidade de Publicações por País e percentual correspondente da base Scopus

\begin{tabular}{c|c|c}
\hline País & Artigos & \% de 246 \\
\hline Inglaterra & 49 & $19 \%$ \\
\hline Estados Unidos & 34 & $14 \%$ \\
\hline Espanha & 24 & $10 \%$ \\
\hline China & 14 & $6 \%$ \\
\hline Austrália & 12 & $4 \%$ \\
\hline Itália & 9 & $4 \%$ \\
\hline Malásia & 9 & $4 \%$ \\
\hline Holanda & 9 & $3 \%$ \\
\hline Alemanha & 8 & $3 \%$ \\
\hline Finlândia & 7 & $28 \%$ \\
\hline Outros & $\mathbf{7 1}$ & $\mathbf{1 0 0 \%}$ \\
\hline Total & $\mathbf{2 4 6}$ &
\end{tabular}

Fonte: Dados da Pesquisa (2017) 
Observou-se que em ambas as bases os Países que mais publicaram artigos que relacionam educação empreendedora e metodologia de ensino são Inglaterra, Estados Unidos e Espanha, sendo responsáveis por 39,25\% do total de artigos na base WoS e $44 \%$ na base Scopus. Na pesquisa realizada na base de dados WoS, o Brasil figura em $5^{\circ}$ lugar com 7 publicações sobre o tema.

As figuras 1 e 2 apresentam um gráfico da evolução temporal de publicações e sua quantidade por ano, nas bases WoS e Scopus.

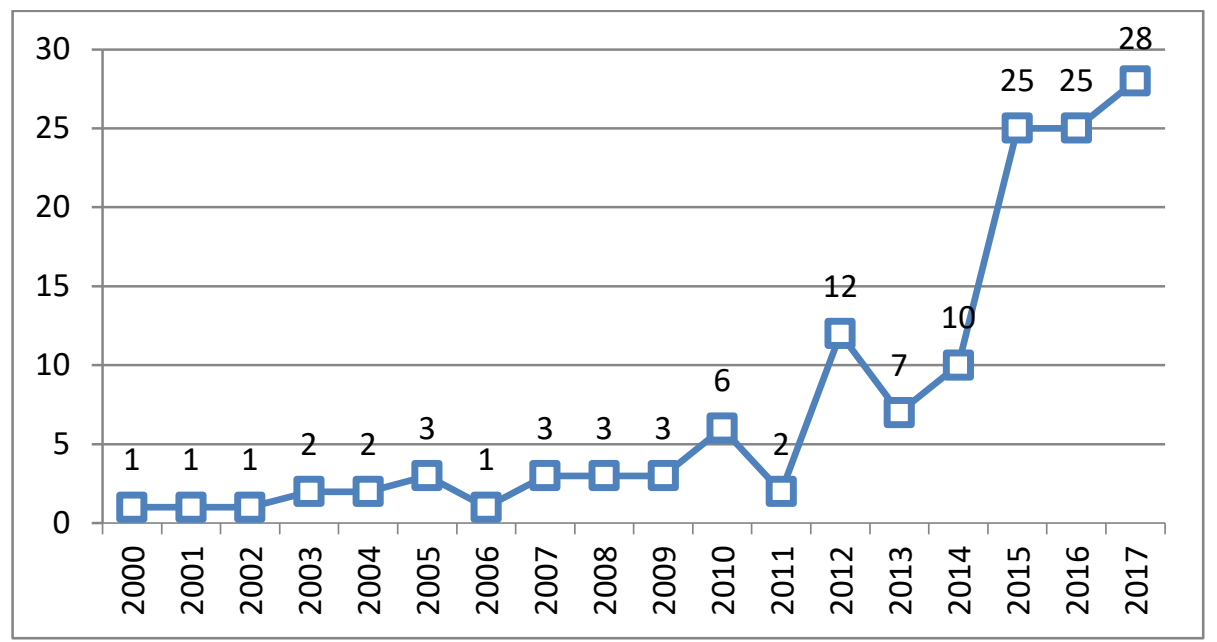

Figura 1. Evolução temporal de publicações na base de dados WoS

Fonte: Dados da Pesquisa

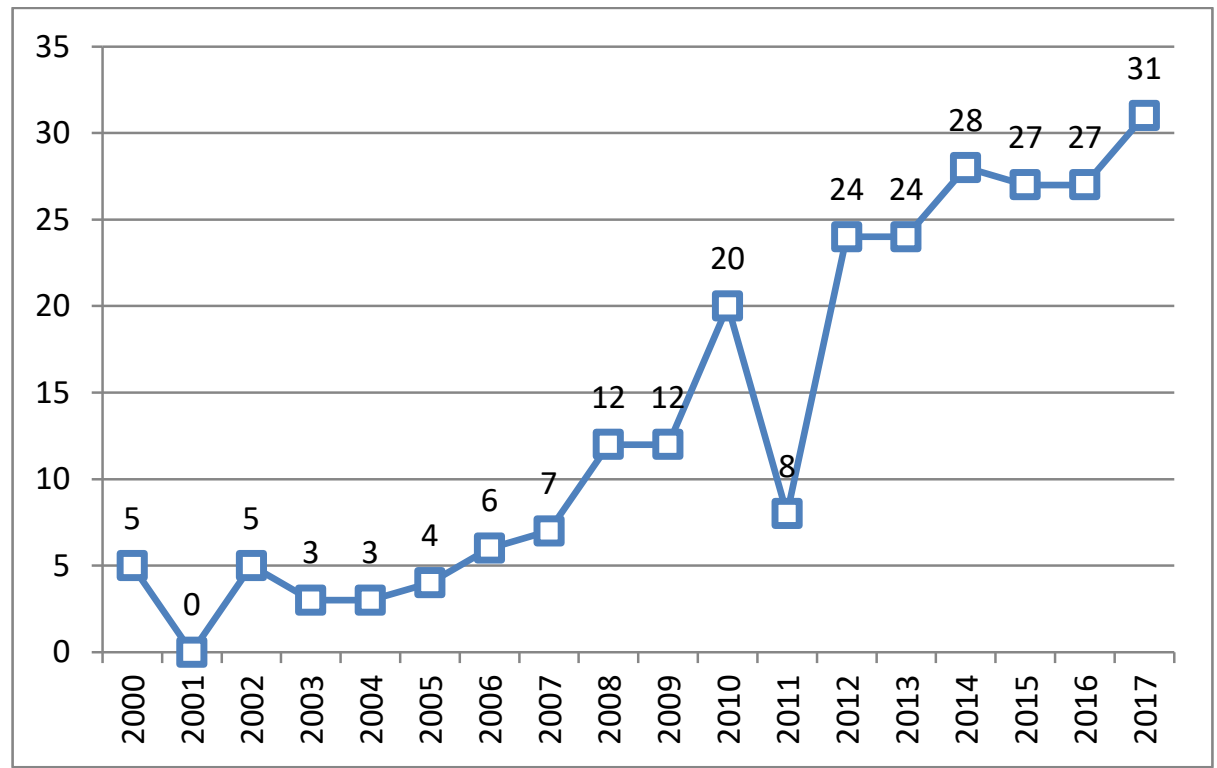

Figura 2. Evolução temporal de publicações na base de dados Scopus

Fonte: Dados da Pesquisa

Dentro do recorte temporal realizado na pesquisa nota-se que as primeiras publicações com a temática educação empreendedora datam do ano 2000. O artigo de autoria de Mauri Laukkanen, "Exploring alternative approaches in high level entrepreneurship education: Creating micromechanism for endogenous regional growth", trata de abordagens alternativas na educação empresarial em universidades, sugerindo que uma universidade possa ser 
conceituada como um sistema de inovação societal (regional) e que a educação empresarial possa não apenas produzir indivíduos competentes orientados para o empreendedorismo, mas também reproduzir os mecanismos sociais que sustentam e facilitam o nascimento e o crescimento de negócios e empresas.

A partir de 2003 nota-se um aumento no número de publicações, mas é a partir de 2012 que este aumento se torna mais significativo, atingindo números substanciais nos anos de 2015, 2016 e 2017.

As Tabelas 3 e 4 mostram os 10 artigos mais citados nas bases de dados WoS (Web of Science) e Scopus.

Tabela 3 - 10 artigos mais citados na base de dados WoS (Web of Science)

\begin{tabular}{|c|c|c|c|c|}
\hline $\begin{array}{l}\text { Total de } \\
\text { citações }\end{array}$ & Título & Autores & Título da Fonte & $\begin{array}{l}\text { Ano de } \\
\text { publicação }\end{array}$ \\
\hline 274 & $\begin{array}{l}\text { Entrepreneurship education - } \\
\text { A systematic review of } \\
\text { evidence }\end{array}$ & $\begin{array}{l}\text { Pittaway, Luke; } \\
\text { Cope, Jason }\end{array}$ & $\begin{array}{l}\text { International Small } \\
\text { Business Journal }\end{array}$ & 2007 \\
\hline 96 & $\begin{array}{l}\text { Entrepreneurship education } \\
\text { reasearch revisited: The case } \\
\text { of higher education }\end{array}$ & $\begin{array}{l}\text { Bechard, JP; } \\
\text { Gregoire, D }\end{array}$ & $\begin{array}{l}\text { Academy of Management } \\
\text { Learning \& Education }\end{array}$ & 2005 \\
\hline 70 & $\begin{array}{l}\text { The development of na } \\
\text { entrepreneurial university }\end{array}$ & $\begin{array}{l}\text { Guerrero, Maribel; } \\
\text { Urbano, David }\end{array}$ & $\begin{array}{l}\text { Journal of Technology } \\
\text { Transfer }\end{array}$ & 2012 \\
\hline 42 & $\begin{array}{l}\text { Entrepreneurship education } \\
\text { and the business school }\end{array}$ & $\begin{array}{l}\text { Binks, M; Starkey, K; } \\
\text { Mahon, CL }\end{array}$ & $\begin{array}{l}\text { Techonology Analysis \& } \\
\text { Strategic Management }\end{array}$ & 2006 \\
\hline 35 & $\begin{array}{l}\text { Economic impact of } \\
\text { Entrepreneurial Universities' } \\
\text { activities: An exploratory } \\
\text { studyof the United Kingdom }\end{array}$ & $\begin{array}{l}\text { Guerrero, } \\
\text { Maribel;Cunningham } \\
\text {, James A.; Urbano, } \\
\text { David }\end{array}$ & Research Policy & 2015 \\
\hline 34 & Mobilizing axes in chemistry & $\begin{array}{l}\text { De Andrade, JB; } \\
\text { Cador, S; Vieira, PC; } \\
\text { Zucco, C; Pinto, AC }\end{array}$ & Química Nova & 2003 \\
\hline 24 & $\begin{array}{l}\text { Understanding the concept of } \\
\text { the entrepreneurial university } \\
\text { from the perspective of higher } \\
\text { education models }\end{array}$ & $\begin{array}{l}\text { Sam, Chanphirun; } \\
\text { van der Sijde, Peter }\end{array}$ & Higher Education & 2014 \\
\hline 22 & $\begin{array}{l}\text { Blending learning: widening } \\
\text { participation in higher } \\
\text { education }\end{array}$ & $\begin{array}{l}\text { Jones, Norah; Lau, } \\
\text { Alice Man Sze }\end{array}$ & $\begin{array}{l}\text { Innovations in Education } \\
\text { and Teaching International }\end{array}$ & 2010 \\
\hline 20 & $\begin{array}{l}\text { Entrepreneurialism and critical } \\
\text { pedagogy: reinventing the } \\
\text { higher education curriculum }\end{array}$ & $\begin{array}{l}\text { Lambert, Cath; } \\
\text { Parker, Andrew; } \\
\text { Neary, Michael }\end{array}$ & $\begin{array}{l}\text { Teaching in Higher } \\
\text { Education }\end{array}$ & 2007 \\
\hline 19 & $\begin{array}{l}\text { Teaching Business In } \\
\text { Tanzania: Evaluating } \\
\text { Participation and Performance }\end{array}$ & $\begin{array}{l}\text { Bjorvatn, Kjetil; } \\
\text { Tungodden, Bertil }\end{array}$ & $\begin{array}{l}\text { Journal of the European } \\
\text { Economic Association }\end{array}$ & 2010 \\
\hline
\end{tabular}

Fonte: Dados da Pesquisa (2017)

Tabela 4 - 10 artigos mais citados na base de dados Scopus

\begin{tabular}{l|l|l|l|l}
\hline $\begin{array}{l}\text { Total de } \\
\text { citações }\end{array}$ & Título & Autores & Título da Fonte & $\begin{array}{l}\text { Ano } \\
\text { publicação }\end{array}$ \\
\hline 128 & $\begin{array}{l}\text { Entrepreneurship education } \\
\text { research revisited: The case of } \\
\text { higher education }\end{array}$ & $\begin{array}{l}\text { Bechard, JP; } \\
\text { Gregoire, D }\end{array}$ & $\begin{array}{l}\text { Academy of Management } \\
\text { Learning \& Education }\end{array}$ & 2005 \\
\hline 104 & $\begin{array}{l}\text { Exploring Alternative } \\
\text { Aproaches in High Level }\end{array}$ & Laukkanen, M. & $\begin{array}{l}\text { Entrepreneurship and } \\
\text { Regional Development }\end{array}$ & 2000 \\
\hline
\end{tabular}




\begin{tabular}{|c|c|c|c|c|}
\hline & $\begin{array}{l}\text { Entrepreneurship Education: } \\
\text { creating micromechanisms for } \\
\text { endogenous regional growth }\end{array}$ & & & \\
\hline 85 & $\begin{array}{l}\text { Universities and Enterprise } \\
\text { Education: responding to the } \\
\text { challenges of the new area }\end{array}$ & Rae, D. & $\begin{array}{l}\text { Journal of Small Business } \\
\text { and Enterprise Development }\end{array}$ & 2010 \\
\hline 84 & $\begin{array}{l}\text { The development of an } \\
\text { entrepreneurial university }\end{array}$ & $\begin{array}{l}\text { Guerrero, Maribel; } \\
\text { Urbano, David }\end{array}$ & $\begin{array}{l}\text { Journal of Technology } \\
\text { Transfer }\end{array}$ & 2012 \\
\hline 73 & $\begin{array}{l}\text { Teaching Piggeons to Dance: } \\
\text { sense and meaning in } \\
\text { entrepreneurship education }\end{array}$ & Hannon, P.D. & Education + Training & 2006 \\
\hline 58 & $\begin{array}{l}\text { Enbedding New } \\
\text { Entrepreneurship Programmes } \\
\text { in UK Higher Education } \\
\text { Institutions: challengers and } \\
\text { considerations }\end{array}$ & $\begin{array}{l}\text { Smith, A.J., } \\
\text { Collins, L.A., } \\
\text { Hannon, P.D. }\end{array}$ & Education + Training & 2006 \\
\hline 56 & $\begin{array}{l}\text { Learning Entrepreneurship in } \\
\text { Higher Education }\end{array}$ & Taatila, V.P. & Education and Training & 2010 \\
\hline 53 & $\begin{array}{l}\text { Teaching and Learning } \\
\text { entrepreneurship for Small } \\
\text { Businesses in the cultural } \\
\text { industries sector }\end{array}$ & $\begin{array}{l}\text { Raffo, C., Lovatt, } \\
\text { A., Banks, M., } \\
\text { O'Connor, J. }\end{array}$ & Education + Training & 2000 \\
\hline 49 & $\begin{array}{l}\text { Entrepreneurship education } \\
\text { and the business school }\end{array}$ & $\begin{array}{l}\text { Binks, M; Starkey, } \\
\text { K; Mahon, CL }\end{array}$ & $\begin{array}{l}\text { Techonology Analysis \& } \\
\text { Strategic Management }\end{array}$ & 2006 \\
\hline 44 & $\begin{array}{l}\text { Economic Impact of } \\
\text { Entrepreneurial Universities' } \\
\text { Activities: Na Exploratory } \\
\text { Study of the United Kingdom }\end{array}$ & $\begin{array}{l}\text { Guerrero, Maribel; } \\
\text { Cunningham, James } \\
\text { A.; Urbano, David }\end{array}$ & Research Policy & 2015 \\
\hline
\end{tabular}

Fonte: Dados da Pesquisa (2017)

$\mathrm{O}$ artigo com maior número de citações na base WoS foi "Entrepreneurship education - A systematic review of the evidence", publicado em 2007 no International Small Business Journal, pelos autores Luke Pittaway e Jason Cope. Os autores apresentam os resultados de uma revisão da literatura acerca de diferentes aspectos da educação empreendedora e concluem que a educação para o empreendedorismo teve um impacto na propensão e intencionalidade dos estudantes graduados. Porém o que não fica claro é se tal educação afetou o nível de empreendedorismo ou se habilita os graduados a se tornarem empresários mais efetivos. Há falta de consenso também sobre o que o empreendedorismo ou a educação empreendedora realmente "é" quando implementada na prática.

$\mathrm{Na}$ base Scopus o artigo com maior número de citações foi "Entrepreneurship education research revisited: The case of higher education”, publicado em 2005 no periódico Academy of Management Learning \& Education, pelo autores Jean Pierre Béchard e Denis Grégoire. Os autores também apresentam uma revisão de literatura com o objetivo de fazer um balanço das principais preocupações educativas no campo da educação empreendedora, por meio da análise de 103 publicações, sob o prisma das teorias contemporâneas de Bertrand (1995) e práticas em educação e concluíram que a literatura é articulada em torno de quatro principais tipos de preocupações educacionais: (i) preocupações com o papel social e econômico da educação empresarial para indivíduos e sociedade, bem como com a instituições próprias do ensino superior; (ii) preocupações com a sistematização de Educação para o empreendedorismo (por exemplo, design instrucional, uso de multimídia ambientes e 
desenvolvimento curricular); (iii) preocupações com o conteúdo que devem ser ensinados e como este deve ser entregue; e (iv) preocupações com as necessidades dos alunos individuais na estruturação das intervenções pedagógicas. Além disso, apontam mais 3 preocupações que permanecem subestimadas, as que procedem teorias social-cognitivo, psico-cognitiva e espiritualista ou ética e argumentam que os estudiosos devem desenvolver uma dupla experiência em pesquisa de gestão e educação. Para isso os autores destacam uma série de referências teóricas e empíricas associadas a diferentes preocupações em pesquisas educacionais.

Após a retirada dos artigos que estavam em duplicidade nas duas bases, o número de artigos válidos para leitura passou a ser 83. Procedeu-se então a leitura detalhada de todos os artigos e foram encontrados 18 artigos onde o tema métodos de ensino de empreendedorismo foi abordado. A Tabela 5 apresenta os títulos dos artigos, seus autores, periódicos ou revistas onde foram publicados, ano de publicação e a abordagem metodológica.

Tabela 5 - Artigos onde o tema métodos de ensino de empreendedorismo foi abordado

\begin{tabular}{|c|c|c|c|c|}
\hline Título & Autor (es) & Journal & Ano & Abordagem \\
\hline $\begin{array}{l}\text { Research on College } \\
\text { Students' Innovation and } \\
\text { Entrepreneurship Education } \\
\text { Mode Based on Social } \\
\text { Participation }\end{array}$ & $\begin{array}{l}\text { Mian Chen, Yuemei } \\
\text { Liu }\end{array}$ & $\begin{array}{l}\text { Revista de la } \\
\text { Facultad de } \\
\text { Ingeniería U.C.V. }\end{array}$ & 2017 & $\begin{array}{l}\text { Níveis de } \\
\text { Experiência }\end{array}$ \\
\hline $\begin{array}{l}\text { Configurações para o Ensino } \\
\text { de Empreendedorismo: Um } \\
\text { Estudo de Caso a Partir do } \\
\text { Currículo de um Curso } \\
\text { Superior de Tecnologia }\end{array}$ & $\begin{array}{l}\text { Erica Pereira Martins, } \\
\text { Márcia Helena Sauaia } \\
\text { Guimarães Rostas }\end{array}$ & Polêm!ca & 2017 & $\begin{array}{l}\text { Método Tradicional } \\
\text { de Ensino }\end{array}$ \\
\hline $\begin{array}{l}\text { Off-campus Entrepreneurship } \\
\text { Tutorial System in China }\end{array}$ & Wen Lixia & $\begin{array}{l}\text { Asian Social } \\
\text { Science }\end{array}$ & 2016 & $\begin{array}{l}\text { Agentes externos } \\
\text { (tutorias) }\end{array}$ \\
\hline $\begin{array}{l}\text { Desarrollo de nuevas ideas de } \\
\text { negocio mediante el } \\
\text { aprendizaje activo }\end{array}$ & $\begin{array}{l}\text { Virginia Rincón } \\
\text { Diez, Pilar Zorrilla } \\
\text { Calvo }\end{array}$ & Opción & 2015 & $\begin{array}{l}\mathrm{ABP}-\text { Abordagem } \\
\text { baseada em projetos }\end{array}$ \\
\hline $\begin{array}{l}\text { Technopreneurship as an } \\
\text { outcomes-based education } \\
\text { tool applied in some } \\
\text { engineering and computing } \\
\text { science programme }\end{array}$ & $\begin{array}{l}\text { Albertson D. Amante } \\
\text { \& Tirso A. Ronquillo }\end{array}$ & $\begin{array}{l}\text { Australasian } \\
\text { Journal of } \\
\text { Engineering } \\
\text { Education }\end{array}$ & 2017 & $\begin{array}{l}\text { Empreendedorismo } \\
\text { tecnológico } \\
\text { (Technopreneurship) }\end{array}$ \\
\hline $\begin{array}{l}\text { A gamified collaborative } \\
\text { course in entrepreneurship: } \\
\text { Focus on objectives and tools }\end{array}$ & Antonaci, et al & $\begin{array}{l}\text { Computers in } \\
\text { Human Behavior }\end{array}$ & 2014 & Jogos \\
\hline $\begin{array}{l}\text { Is Business Creation the } \\
\text { Mean or the End of } \\
\text { Entrepreneurship Education? } \\
\text { A Multiple Case Study } \\
\text { Exploring Teaching Goals in } \\
\text { Entrepreneurship Education }\end{array}$ & $\begin{array}{l}\text { Carlos Albornoz } \\
\text { Pardo }\end{array}$ & $\begin{array}{l}\text { Journal of } \\
\text { Technology } \\
\text { Management \& } \\
\text { Innovation }\end{array}$ & 2013 & $\begin{array}{l}\text { Método Tradicional } \\
\text { de Ensino }\end{array}$ \\
\hline $\begin{array}{l}\text { Serious games and the } \\
\text { development of an } \\
\text { entrepreneurial mindset in } \\
\text { higher education engineering }\end{array}$ & Bellotti, et al & $\begin{array}{l}\text { Entertainment } \\
\text { Computing }\end{array}$ & 2014 & Jogos \\
\hline
\end{tabular}




\begin{tabular}{|c|c|c|c|c|}
\hline students & & & & \\
\hline $\begin{array}{l}\text { Creative disciplines } \\
\text { education: a model for } \\
\text { assessing ideas in } \\
\text { entrepreneurship education? }\end{array}$ & $\begin{array}{l}\text { Charlotte Carey and } \\
\text { Harry Matlay }\end{array}$ & $\begin{array}{l}\text { Education and } \\
\text { Training }\end{array}$ & 2010 & $\begin{array}{l}\text { Abordagem } \\
\text { experiencial }\end{array}$ \\
\hline $\begin{array}{l}\text { Learning-by-doing as an } \\
\text { approach to teaching social } \\
\text { entrepreneurship }\end{array}$ & $\begin{array}{l}\text { Jane Chang, } \\
\text { Abdelhafid } \\
\text { Benamraoui \& } \\
\text { Alison Rieple }\end{array}$ & $\begin{array}{l}\text { Innovations in } \\
\text { Education and } \\
\text { Teaching } \\
\text { International }\end{array}$ & 2013 & $\begin{array}{l}\text { Abordagem } \\
\text { experiencial }\end{array}$ \\
\hline $\begin{array}{l}\text { Tourism Education: What } \\
\text { about entrepreneurial skills? }\end{array}$ & $\begin{array}{l}\text { Ana Dias Daniel, Rui } \\
\text { Augusto Costa, } \\
\text { Mariana Pita, Carlos } \\
\text { Costa }\end{array}$ & $\begin{array}{l}\text { Journal of } \\
\text { Hospitality and } \\
\text { Tourism } \\
\text { Management }\end{array}$ & 2017 & $\begin{array}{l}\mathrm{ABP} / \text { design } \\
\text { thinking }\end{array}$ \\
\hline $\begin{array}{l}\text { Involving the Entrepreneurial } \\
\text { Role Model: A Possible } \\
\text { Development for } \\
\text { Entrepreneurship Education }\end{array}$ & $\begin{array}{l}\text { Rahman, Hafiz and } \\
\text { Day, John }\end{array}$ & $\begin{array}{l}\text { Journal of } \\
\text { Entrepreneurship } \\
\text { Education }\end{array}$ & 2014 & $\begin{array}{l}\text { Agentes externos } \\
\text { (tutorias) }\end{array}$ \\
\hline $\begin{array}{l}\text { Entrepreneurship Education } \\
\text { and Training in Higher } \\
\text { Educational Institutions in } \\
\text { Ghana }\end{array}$ & $\begin{array}{l}\text { Smile Dzisi \& } \\
\text { Franklin Odoom }\end{array}$ & J Int Entrep & 2017 & $\begin{array}{l}\text { Método Tradicional } \\
\text { de Ensino }\end{array}$ \\
\hline $\begin{array}{l}\text { The Role of Entrepreneurship } \\
\text { Program Models and } \\
\text { Experiential Activities on } \\
\text { Engineering Student } \\
\text { Outcomes }\end{array}$ & $\begin{array}{l}\text { Nathalie Duval- } \\
\text { Couetil, Angela } \\
\text { Shartrand, Teri Reed }\end{array}$ & $\begin{array}{l}\text { Advances in } \\
\text { Engineering } \\
\text { Education }\end{array}$ & 2016 & $\begin{array}{l}\text { Abordagem } \\
\text { experiencial }\end{array}$ \\
\hline $\begin{array}{l}\text { Incorporating Student- } \\
\text { Centred Learning in } \\
\text { Innovation and } \\
\text { Entrepreneurship Education }\end{array}$ & $\begin{array}{l}\text { Saskia J.M. Harkema } \\
\text { e Henk Schout }\end{array}$ & $\begin{array}{l}\text { European Journal of } \\
\text { Education }\end{array}$ & 2008 & $\begin{array}{l}\text { Método Tradicional } \\
\text { de Ensino }\end{array}$ \\
\hline $\begin{array}{l}\text { Innovating entrepreneurial } \\
\text { pedagogy: examples from } \\
\text { France and Germany }\end{array}$ & $\begin{array}{l}\text { Rita Klapper Silke } \\
\text { Tegtmeier }\end{array}$ & $\begin{array}{l}\text { Journal of Small } \\
\text { Business and } \\
\text { Enterprise } \\
\text { Development }\end{array}$ & 2010 & $\begin{array}{l}\text { Abordagem } \\
\text { experiencial }\end{array}$ \\
\hline $\begin{array}{l}\text { Learning entrepreneurship in } \\
\text { Higher Education }\end{array}$ & Vesa P. Taatila & $\begin{array}{l}\text { Education and } \\
\text { Training }\end{array}$ & 2010 & $\begin{array}{l}\text { Abordagem } \\
\text { experiencial }\end{array}$ \\
\hline $\begin{array}{l}\text { Experiential learning as } \\
\text { teaching strategy for } \\
\text { entrepreneurship: assessment } \\
\text { of a Brazilian experience }\end{array}$ & Tete, et al & $\begin{array}{l}\text { Int. J. Innovation } \\
\text { and Learning }\end{array}$ & 2014 & $\begin{array}{l}\text { Abordagem } \\
\text { experiencial }\end{array}$ \\
\hline
\end{tabular}

Fonte: Desenvolvido pelo autor (2017)

Para autores como Lopes (2010), a educação empreendedora faz uso de métodos que permitam ao aluno aprender fazendo, pois o indivíduo se defronta com eventos críticos que o forçam a pensar de maneira diferente, buscando saídas e alternativas e aprendendo com a experiência e com o processo. Ainda segundo a autora, educação empreendedora se relaciona com a aprendizagem experiencial de David A. Kolb, sob essa perspectiva o homem é um ser integrado ao meio natural e cultural, capaz de aprender a partir de sua experiência motivado 
por seus propósitos, ou seja, obtém aprendizado que lhe faça sentido (Pimentel, 2007), e está relacionada também com pedagogias, tais como, aprendizagem pela ação, aprendizagem contextual, aprendizagem centrada em problemas e aprendizagem cooperativa. A seguir, uma descrição mais detalhada dos artigos relacionados na Tabela 5.

Observou-se que dos 18 artigos relacionados na Tabela 5, 15 trazem abordagens de ensino de empreendedorismo baseadas em métodos ativos de ensino: Jogos de negócios, ensino colaborativo baseado em ABP, métodos experienciais, aprender fazendo, método baseado em projetos combinado com a ferramenta design thinking, utilização de agentes externos no processo de aprendizado, método baseado em participação social. Também foi observado que essas metodologias começaram a ser abordadas em publicações a partir do ano de 2010, o que caracteriza uma tendência recente no ensino de empreendedorismo.

Métodos mais tradicionais, onde a elaboração do plano de negócios e métodos de ensino baseados em exposições, palestras, debates em sala de aula, que objetivam despertar a consciência empreendedora do aluno, foram abordados em 3 artigos.

$\mathrm{O}$ artigo "Research on Practice Teaching Model of Entrepreneurship Education based on Experience Degree”, dos autores Changyun Wan, Aidi Xu, Xueqing Zhang, Jiesheng Wu, traz uma proposta de ensino de empreendedorismo baseado na análise de níveis de experiência dos alunos, combinando conhecimento empresarial e treinamento de habilidades empresariais, como um modo de educação prática e efetiva. Os graus de experiência são 4: (i) nível 1 - experiência de educação do espírito empresarial, (ii) nível 2 - experiência de educação de simulação corporativa, (iii) nível 3 - experiência em educação empresarial experimental e (iv) nível 4 - experiência de educação em operação empresarial. Os autores pontuam que está prática de educação empreendedora (por níveis de experiência) são para diferentes níveis de talentos e que é de grande importância que os círculos acadêmicos e educacionais da China se adequem a esse modelo como reforma da educação.

O sistema de tutoria fora do campus, que é marca de Oxford, e consiste em oferecer aos graduandos um tutor de fora da universidade (empresário, estudioso, líderes, celebridades), que se interessam pelo trabalho do graduando, critica, incentiva, inspira e guiao, é abordado no artigo "Off-campus Entrepreneurship Tutorial System in China", de Wen Lixia. O autor defende a implementação do sistema de tutoria em empreendedorismo com base no Tutorial de Oxford, fornecendo orientação e segurança para o avanço da educação inovadora e empresarial de instituições superiores na China. Universidades da China e cerca de 100 escolas aplicam o sistema parcialmente e embora o sistema tenha feito progressos, ele ainda não alcançou os resultados esperados, tendo ainda, muitos aspectos a serem melhorados, como, número maior de estudantes participando, conteúdo inespecífico para as orientações, apoio insuficiente das universidades.

O impacto da abordagem de ensino "Aprendizagem Baseada em Projetos (ABP)" foi analisado no artigo "Desarrollo de nuevas ideas de negocio mediante el aprendizaje activo" de Virginia Rincón Diez e Pilar Zorrilla Calvo. As autoras analisaram e apresentaram as vantagens da aplicação de tal metodologia para os alunos da Faculdade de Ciências Econômicas e Empresariais do País Basco, nas disciplinas "Decisões de Produto e Preço" e Distribuição Comercial", durante os anos letivos de 2013-2014 e 2014-2015. O objetivo foi analisar o impacto da competência "Capacidade, Inovação e Espírito Empresarial", foram aplicados 154 questionários no primeiro ano e 204 no segundo. Os resultados mostraram que a aplicação da metodologia ABP favorece a conquista da competência CIEE. 
Technopreneurship (empreendedorismo tecnológico) é o empreendedorismo aplicado em um contexto tecnológico intensivo. A Universidade Estadual de Batangas nas Filipinas desenvolveu nos cursos de Bacharel em Ciências em Engenharia Eletrônica, Engenharia Informática, Ciência da Computação e Tecnologia da Informação, o curso de Technopreneurship, com o objetivo de desenvolver a capacidade dos alunos de se comunicar efetivamente de atuar em equipes multidisciplinares; e projetar e implementar um MVPs (Minimum Viable Product). O objetivo do estudo foi realizar análise e avaliação da eficácia do método BatStateU de Technopreneurship na obtenção de resultados escolares. Uma pesquisa on line dividida em 3 partes (i) perfil e antecedentes educacionais (ii) fatores que motivam os alunos a prosseguir (ou não) uma carreira tecnológica (iii) nível de conhecimento ou habilidades em algumas áreas do empreendimento tecnológico, era aplicada antes e depois da aula com os alunos participantes do curso. $O$ resultado mostrou uma mudança significativa na mentalidade dos alunos para configurar seus negócios após a graduação, foi uma boa indicação sobre o impacto positivo do programa.

O documento "A gamified collaborative course in entrepreneurship: Focus on objectives and tools", de Antonacci et al descreve a lógica dos cursos avançados e colaborativos para estudantes universitários, desenvolvidos e implantados no âmbito do projeto SG (simulando o empreendedorismo por meio de Jogos Sérios), uma pioneira tentativa de "gamificar" um curso colaborativo no campo da educação para empreendedorismo em universidades técnicas não empresariais que objetiva estimular mentalidades inovadoras e empreendedoras de estudantes de ensino superior de faculdades não comerciais e fornecer-lhes algumas das habilidades teóricas e operacionais necessárias. Foram realizados cursos específicos de eSG que fazem um uso extensivo de Jogos Sérios (juntamente com outros meios de comunicação mais tradicionais) em três países parceiros (Itália, Espanha e Países Baixos) para os três níveis de estudantes: Bacharelado, Mestrado, $\mathrm{PhD}$. Todos os jogos foram analisados à luz de um modelo baseado na identificação das competências de empreendedorismo e os resultados e conhecimentos adquiridos no projeto eSG poderiam servir para o desenvolvimento de novos SGs mais eficientes, bem como, ampliar a educação empreendedora para outros níveis escolares, permitindo ações anteriores para apoiar o desenvolvimento da mentalidade empreendedora.

Um relato sobre sua experiência no projeto eSG (simulando empreendedorismo por meio de jogos sérios) e uma avaliação na aplicação dos jogos pode ser lido no artigo "Serious games and the development of an entrepreneurial mindset in higher education engineering students", de Bellotti et al. Em seu trabalho o autor apresenta uma visão geral dos SGs relevantes disponíveis no mercado e identifica, através de uma análise especializada, os principais benefícios e questões sobre a sua adoção no ensino do empreendedorismo para os alunos-alvo. $\mathrm{O}$ autor conclui que os jogos foram percebidos como ferramenta útil para apresentar assuntos complexos e para a prática de procedimentos operacionais, entretanto, não foram se trata de uma interface muito divertida, o que não envolveu e motivou o jogador profundamente. Essa questão foi colocada como importante para design futuro dos jogos, com vistas a engajar mais os usuários.

As chamadas disciplinas criativas, ou seja, as caracterizadas por ambientes de aprendizagem experienciais, baseados em projetos e avaliações regulares por pares são abordadas no artigo "Creative disciplines education: a model for assessing ideas in entrepreneurship education?", de Charlotte Carey and Harry Matlay. Os autores exploram as formas como essas disciplinas são ensinadas, entregues e avaliadas e como a avaliação 
contribui para o desenvolvimento da educação empresarial no Reino Unido. Por meio da análise de dados de três fontes: (i) entrevistas com empresários do setor criativo, (ii) anúncios de empregos para professores e (iii) uma pesquisa com educadores de disciplinas criativas na Educação Superior. O método utilizado para análise dos dados coletados foi a triangulação múltipla e as conclusões do estudos são contextualizadas principalmente sobre as formas de avaliação e perfil dos educadores. No âmbito das avaliações concluiu-se que em primeiro lugar, são feitas de maneira formativa, por pares habilitados e com técnicas baseadas em discussões, em segundo lugar, os alunos são frequentemente estimulados a apresentarem trabalhos e ideias em público em terceiro, o processo de avaliação está fortemente posicionado dentro do contexto de uma crítica e por último as técnicas de avaliação de ideias poderiam ser transferidas para ensino de empreendedorismo. No que tange perfil dos educadores o aspecto fundamental nos achados foi a relação do educador com a indústria, o que oferece um contexto de "mundo real" para os alunos.

No artigo "Learning by doing as an approach to teaching social entrepreneurship", dos autores Jane Chang, Abdelhafid Benamraoui e Alison Rieple, o ensino experiencial por meio do método "aprender fazendo" é abordado como ferramenta para o ensino de empreendedorismo social. Um programa que envolve estudantes em uma abordagem de ensino inovadora e que utiliza uma atividade de angariação de fundos como um método de aquisição de habilidades e conhecimentos, bem como a adoção de uma plataforma de aprendizagem em sinergia com empreendedores sociais, funcionários da universidade e não acadêmicos e empresários locais que patrocinaram os esforços de angariação de fundos. Os resultados apresentados após a aplicação do método indicaram que aprender por ação permite o desenvolvimento de habilidades empresariais, além de tornar os alunos mais eficazes no trabalho em equipe e na formulação e aplicação de estratégias comerciais.

Após constatar que há uma lacuna nos cursos de graduação em turismo, ocasionada pela falta de disciplinas que ajudem os estudantes a desenvolverem habilidades empresariais, o artigo "Tourism Education: What about entrepreneurial skills?" dos autores Ana Dias Daniel, Rui Augusto Costa*, Mariana Pita, Carlos Costa apresenta um programa chamado "Learn to be", que tem uma metodologia de aprendizado baseada em projetos, suportada por processos de design thinking. Os alunos são desafiados a promover soluções viáveis para problemas reais que são promovidos por organizações públicas e privadas. Um questionário de feedback também foi desenvolvido a fim de se avaliar os impactos da aplicação do método sobre os estudantes. $\mathrm{O}$ autor concluiu que a educação para o empreendedorismo foi considerada relevante para futuras perspectivas de emprego, bem como, os alunos tiveram habilidades não cognitivas inerentes ao setor de turismo aprimoradas e o estudo também foi relevante para identificar boas práticas e propor diretrizes para criação de curriculuns para o desenvolvimento de habilidades empresariais.

É importante ter contato com pessoas que possam ser modelos para a construção de uma carreira empreendedora? No artigo "Involving the entrepreneurial role model: a possible development for entrepreneurship education.", de Hafiz Rahman e John Day, a relação dos estudantes com pessoas que possam ser modelos é mostrada como influência positiva para suas motivações empresariais, bem como, a escolha de uma carreira futura como empreendedores. Pais, empresários e professores são os atores mais indicados para desempenhar esse papel. Professores assumem as tarefas de facilitador na busca dos alunos pelo conhecimento sobre empreendedorismo, já os pais e empresários podem atuar como fonte de aprendizagem empresarial informal. Particularmente, os empresários podem ser 
tornar "pais ou mães" do negócio, estabelecendo com os estudantes uma longa relação informal. $\mathrm{O}$ modelo foi aplicado em uma universidade da Indonésia, e embora os alunos tenham reagido positivamente para a existência desses modelos, o autor deixa claro que devem ser estabelecidos arranjos e configurações adequados em termos de disposição curricular para apoiar a implantação, aliado a disponibilidade de instalações e infraestruturas de apoio.

Uma pesquisa realizada com 501 alunos matriculados em cursos de engenharia de nível superior de três instituições que ofereceram três modelos diferentes de educação para empreendedorismo: (i) incorporados na engenharia e compostos por uma sequência de curso; (ii) originários da engenharia e resultando em menor acadêmico e (iii) um programa multidisciplinar universitário, resultando em um certificado acadêmico, foi abordada no artigo "The Role of Entrepreneurship Program Models and Experiential Activities on Engineering Student Outcomes". Os autores Nathalie Duval-Couetil, Angela Shartrand e Teri Reed objetivaram com o estudo responder a questões como, quais programas são mais eficazes e que tipo de educação empreendedora os alunos precisam para que tirem o maior proveito disso. Os resultados indicaram que as maiores percepções foram associadas ao envolvimento em atividades de aprendizagem experiencial, bem como, os estudantes que frequentaram a instituição com o programa multidisciplinar classificaram suas habilidades empresarias mais altas em relação aos que participaram da pesquisa e estudaram nas instituições com programas incorporados em departamentos de engenharia.

No artigo "Incorporating student-centred learning in innovation and entrepreneurship education”, de Saskia J. M. Harkema e Henk Schout foi apresentado um programa de ensino de empreendedorismo centrado no aluno, integrando inovação e empreendedorismo, com o objetivo de desenvolver no aluno competências para se tornar empreendedor individual ou usar o conhecimento para empreender dentro de uma organização. O programa consistiu de um curso de 20 semanas em período integral e foi aplicado na Universidade de Educação Profissional de Haia. Os autores concluem que embora não haja muitos estudos que meçam o impacto de tais abordagens no desenvolvimento empreendedor do aluno, é válido investir em educação empreendedora e acrescentam que mais de 150 alunos já aderiram ao programa.

$\mathrm{O}$ documento "Innovating entrepreneurial pedagogy: examples from France and Germany", de Rita Klapper e Silke Tegtmeier, baseia-se em dois estudos de caso e visa comparar e contrastar a pedagogia empresarial inovadora em dois cenários europeus diferentes, a França e a Alemanha. No caso alemão, a gestão e outras disciplinas trabalham em conjunto para criar o exemplo da "empresa de prática", e na França, teorias de redes e ciências cognitivas são reunidas para criar uma nova abordagem para aprender sobre o empreendedorismo. Ambas as abordagens destacam a importância do desenvolvimento pessoal dos participantes, capacitando-os para serem proativos. Os estudos concluíram que ambas as abordagens, embora diferentes em foco, aplicação e extensão, são potencialmente complementares. Assim, a ferramenta de análise de rede poderia ser integrada no conceito de empresa prática, já que os méritos da ferramenta e sua aplicação em situações de inicialização foram reconhecidos. Igualmente interessante é o conceito mais amplo da empresa de consultoria para o parceiro francês, que salienta o potencial de novas tentativas colaborativas no desenvolvimento de ferramentas pedagógicas inovadoras conjuntas.

Baseado na necessidade crescente de formar empreendedores nas instituições de ensino superior, o artigo "Learning entrepreneurship in higher education", de Vesa P. Taatila, apresenta os resultados de um estudo de 4 casos bem sucedidos de ambientes de 
aprendizagem em Instituições de Ensino Superior, voltados para a formação de competências empresarias, não apenas um local para se adquirir conhecimentos acadêmicos acerca do empreendedorismo. A ideia defendida no artigo é que deve haver uma mudança dos modelos de transmissão de ensino de "aprendizagem sobre" para "aprendizagem para", o que ofereceria aos alunos técnicas que poderiam ser aplicadas de forma mais realista. $\mathrm{O}$ foco dos estudos está na educação "para" empresas - referente à preparação para carreira e auto emprego, e educação "em empresa" - treinamento de gestão para empreendedores estabelecidos, e os casos estudados são exemplos de métodos de ensino experienciais. $\mathrm{O}$ estudo sugere que as universidades se concentrem em proporcionar um aprendizado mais voltado para o "para" e "em" empresas, que o ensino seja centrado no aluno e ajustarem sua filosofia de pedagogia para suportar abordagens mais pragmáticas.

Um estudo em uma universidade brasileira localizada em Rondônia apresenta uma abordagem experiencial de ensino de empreendedorismo e analisa os resultados obtidos em uma pesquisa realizada com os alunos da universidade. O estudo foi realizado com 90 alunos do curso de Administração de Empresas da UFRO, no ano de 2009. Os resultados se mostraram positivos quanto às intenções dos estudantes em se tornarem empresários, quanto à identificação de negócios e oportunidades e trabalho em equipe, e também sobre habilidades no planejamento de novos empreendimentos, criação e desenvolvimento de marcas.

Os artigos "Configurações para o ensino de empreendedorismo: um estudo de caso a partir do currículo de um curso superior de tecnologia”, das autoras Erica Pereira Martins e Márcia Helena Sauaia Guimarães Rostas, "Is business creation the mean or the end of entrepreneurship education? A multiple case study exploring teaching goals in entrepreneurship education", de Carlos Albernoz Pardo e "Entrepreneurship Education and Training in Higher Educational Institutions in Ghana", dos autores Smile Dzisi e Franklin Odoom, trazem análises de estudos de casos e pesquisas realizadas em Instituições de Ensino Superior, levando em conta curriculum, objetivos de ensino de instrutores da disciplina na área de empreendedorismo e como as disciplinas relacionadas à educação empreendedora estão sendo ofertadas. Todos concluem que as abordagens metodológicas tradicionais são aplicadas e sugerem que tais abordagens sejam reavaliadas. O último artigo pontua ainda que os métodos experienciais deveriam ser trabalhados com mais ênfase.

\section{Considerações finais}

Historicamente, uma variedade de curriculuns e métodos de ensino tem sido usados em todos os tipos de cursos de empreendedorismo em nível superior (Rideout e Gray, 2013). Atualmente, as práticas pedagógicas em educação empreendedora parecem ser um pouco ecléticas e diversificadas, embora as abordagens como, gerenciamento de pequenos negócios, as tradicionais palestras e estudo de casos, continuem sendo bastante aplicadas, observa-se uma tendência ao crescimento das práticas de tecnoempreendedorismo, ensino andragógico e experiencial por meio de jogos, simulações e até mesmo criações de risco real.

O presente estudo identificou as publicações acerca do tema educação empreendedora e métodos de ensino de empreendedorismo em instituições de ensino superior, utilizando as bases de dados WoS e Scopus. A busca gerou um número de 83 artigos, dos quais 18 tratavam especificamente de métodos de ensino.

O método de ensino mais abordado nos artigos foi o de aprendizagem experiencial, caracterizada por abordagens de jogos, métodos de ensino ativos, métodos baseados em projetos / design thinking, participação social, utilização de agentes externos / tutores no 
processo de aprendizado e o learning by doing (aprender fazendo), o que demonstra uma tendência à utilização cada vez maior de tais abordagens no ensino de empreendedorismo, pois, como foi observado nos estudos analisados, métodos experienciais tendem a desenvolver de forma mais efetiva a consciência empreendedora no aluno, despertando o interesse em se tornar empreendedor autônomo. Entretanto, os métodos tradicionais de ensino de empreendedorismo, como elaboração de planos de negócios, palestras sobre o tema, debates em sala de aula se mantém como abordagens utilizadas para despertar a consciência empreendedora nos alunos.

O que se conclui desse estudo é que ainda não há consenso sobre qual método é mais efetivo no ensino de empreendedorismo, bem como, ainda há poucos estudos na área, mas as pesquisas no campo estão cada vez mais efetivas e abrindo espaço para novas discussões e estudos mais aprofundados acerca do tema, como por exemplo, o estudo dos impactos e da efetividade de tais abordagens após a formação do aluno.

\section{Referências}

Béchard J.P, G. D. (2005). Entrepreneurship Educaton Research Revisited: The Case of Higher Education. Academy of Management Learning \& Education, IV, pp. 22-43.

Fayolle, A. (2013). Personal Views on the Future of Entrepreneurship Education. Entrepreneurship and Regional Development: An International Journal, 25, pp. 692701.

Gerhardt, T. E. (2009). Métodos de Pesquisa. Porto Alegre: UFRGS.

Gil, A. (2002). Como Elaborar Projetos de Pesquisa. São Paulo: Atlas.

Kuratko, D. F. (2005). The Emergence of Entrepreneurship Education: Development, Changes, and Challenges. Entrepreneurship Theory and Practice, pp. 577-597.

Lopes, R. M. (2010). Referenciais para Educação Empreendedora. In: R. M. Lopes, Educação Empreendedora: conceitos, modelos e práticas (pp. 17-44). São Paulo: Elsevier.

Marcelo, J. H. (2013). Estudo Bibliométrico sobre a Produção Científica no Campo da Sociologia da Ciência. Informação \& Informação, 138-153.

Moberg, K. (2014). Assessing the Impact of Entrepreneurship Education - From ABC to PHD ( $1^{\mathrm{a}}$ ed.). Copenhagen, Dinamarca.

Pimentel, A. (2007). A Teoria da Aprendizagem Experiencial como Alicerce de Estudos sobre Desenvolvimento Profissional. Estudos de Psicologia, 159-168.

Rideout, E., \& Gray, D. (2013). Does entrepreneurship education really works? A review and methodological critique of the empirical literature on the effects of University-based entrepreneurship education. Journal of Small Business Management, pp. 329-351.

Vanevenhoven, J., \& Liguori, E. (2013). The Impact of Entrepreneurship Education: Introducing the Entrepreneurship Education Project. (G. T. Solomon, Ed.) Journal of Small Business Management, 51, pp. 315-328.

Winkel, D., Vanevenhoven, J., Drago, W. A., \& Clements, C. (2013). The Structure and Scope of Entrepreneurship Programs in Higher Education Around the World. Journal of Entrepreneurship Education, 16, pp. 15-29. 